\title{
Model-based aviation advice on distal volcanic ash clouds by assimilating aircraft in situ measurements
}

\author{
Guangliang Fu' ${ }^{1}$, Arnold Heemink ${ }^{1}$, Sha Lu ${ }^{1}$, Arjo Segers ${ }^{2}$, Konradin Weber ${ }^{3}$, and Hai-Xiang Lin ${ }^{1}$ \\ ${ }^{1}$ Delft University of Technology, Delft Institute of Applied Mathematics, Mekelweg 4, 2628 CD Delft, the Netherlands \\ ${ }^{2}$ TNO, Department of Climate, Air and Sustainability, P.O. Box 80015, 3508 TA Utrecht, the Netherlands \\ ${ }^{3}$ University of Applied Sciences, Environmental Measurement Techniques, Josef-Gockeln-Str. 9, 40474 Düsseldorf, Germany
}

Correspondence to: Guangliang Fu (g.fu@tudelft.nl)

Received: 23 February 2016 - Published in Atmos. Chem. Phys. Discuss.: 21 March 2016

Revised: 31 May 2016 - Accepted: 12 July 2016 - Published: 26 July 2016

\begin{abstract}
The forecast accuracy of distal volcanic ash clouds is important for providing valid aviation advice during volcanic ash eruption. However, because the distal part of volcanic ash plume is far from the volcano, the influence of eruption information on this part becomes rather indirect and uncertain, resulting in inaccurate volcanic ash forecasts in these distal areas. In our approach, we use real-life aircraft in situ observations, measured in the northwestern part of Germany during the 2010 Eyjafjallajökull eruption, in an ensemble-based data assimilation system combined with a volcanic ash transport model to investigate the potential improvement on the forecast accuracy with regard to the distal volcanic ash plume. We show that the error of the analyzed volcanic ash state can be significantly reduced through assimilating real-life in situ measurements. After a continuous assimilation, it is shown that the aviation advice for Germany, the Netherlands and Luxembourg can be significantly improved. We suggest that with suitable aircrafts measuring once per day across the distal volcanic ash plume, the description and prediction of volcanic ash clouds in these areas can be greatly improved.
\end{abstract}

\section{Introduction}

Ash produced during explosive volcanic eruptions can cause serious impacts close to the volcano as well as at great distances (Melville, 1986). Turbine engines are particularly threatened by ingestion of airborne ash, and aircraft surfaces may be subject to abrasion and in the longer-term corrosion (Casadevall, 1994). For example, the sudden eruption of the icelandic Eyjafjallajökull volcano (April-May 2010), had caused an all-time airspace closure in Europe leading to an enormous loss for the global economy (Bonadonna et al., 2012). Considering the huge impacts on aviation society, a lot of research has been focusing on improving volcanic ash forecast accuracy to efficiently lower the aviation impacts (Eliasson et al., 2011; Schumann et al., 2011; Gudmundsson et al., 2012). Currently a lot of approaches, employing satellite-based (Prata and Prata, 2012; Stohl et al., 2011; Lu et al., 2016) or ground-based (Emeis et al., 2011) measurements, focus on improving the estimation of eruption source parameters (ESPs) such as plume height and mass eruption rate. These are very important for a good estimation of volcanic ash emission. However, for the volcanic ash plume far from the volcano which could be very important for local aviation, more accurate ESPs alone will not be very useful. This is mainly because (1) compared to ESPs, the plume transport becomes more and more dominant as the distance to the volcano increases (Macedonio et al., 2016); (2) the small errors in ESPs can accumulate into large errors in predicted ash concentrations after a large transport distance (Webster et al., 2012). Therefore, additional observation data, e.g., direct observations of distal volcanic ash plume must be employed to improve the aviation advice over continental Europe.

Ensemble-based data assimilation is one of the most commonly used approaches for real-time forecasting problems (Evensen, 2009), which can create accurate initial conditions for model runs by continuously using direct measurements (Zehner, 2010). At every assimilation step, a first guess (forecast) is generated from the previous model simulation, and then this forecast is modified to be more in agreement with 
the available observations. This approach is very effective for regional forecasting. For employment of ensemble-based data assimilation, in situ measurements are the optimal type of observations (Evensen, 2009). Although satellite measurements are considered as the most commonly used volcanic ash observations based on their large detection domain and long-time continuous output data, they are not directly suited for data assimilation systems. This is because satellite observations are often not direct measurements of the quantity of interest, but optical property measurements. Therefore the aerosol quantity needs to be derived by a retrieval process or a complex observation operator. Moreover, satellite data are often two-dimensional (2-D), and thus lack sufficient vertical resolution (Bocquet et al., 2015). Note that some satellites can provide very detailed vertical information on plumes (e.g., Cloud-Aerosol Lidar with Orthogonal Polarization (CALIOP) lidar measurements) but are spatially sparse (Winker et al., 2012). Fortunately, the in situ volcanic ash state variables can be directly and accurately measured nowadays by means of airborne observations of volcanic ash (Weber et al., 2012). These aircraft-based measurements can be obtained in the boundaries of volcanic ash plume, which are probably the most direct volcanic ash observations possible. They have some unique advantages. First, aircraft data are usually obtained from optical particle counters. Thus real-time particle concentration observation can be directly measured (Weber et al., 2012). Second, the in situ aircraft measurements can be compared directly to a 3-D model state variable (e.g., concentration). In contrast, other measurements such as satellite data and lidar data observe optical properties that contain indirect information about concentrations and require further modeling and assumptions for getting translated into concentration estimates. Note that in this study volcanic ash state refers to the whole volcanic ash plume, while volcanic ash state variables represent pointto-point volcanic ash concentrations inside the ash plume. Third, an aircraft is flexible in flight route to follow the ash clouds. Although an aircraft measurement plan is usually designed beforehand for a region and/or altitude of interest, the aircraft operator can adjust the detailed route according to the real conditions (e.g., ash concentration level, wind direction) of the plume transport in order to always obtain useful volcanic ash concentrations (Weber et al., 2012).

Recently in the application of volcanic ash transport, the benefit of aircraft in situ observations in an ensemble Kalman filter (EnKF) system has been studied (Fu et al., 2015). It was shown using so-called twin experiments that ensemble-based data assimilation is in principle able to combine the aircraft in situ measurements with a volcanic ash transport and dispersion model (VATDM) to make improvements on volcanic ash estimation close to the eruption location. In that study, the focus was on the near-volcano areas where the uncertainties on plume height and mass eruption rate turned out to have a large influence on the estimates of the forecasted ash concentrations. However, for distal volcanic ash plume, these eruption parameters hardly improve the forecasts over a long distance. A larger mass eruption rate may cause the distal volcanic ash plume to spread stronger and wider after a long time period. But this potential effect can be significantly influenced or even canceled out by a combination of a number of elusive physical factors over a long time period such as wind speed and direction. Thus the results on near-volcano areas cannot be directly employed for far-volcano regions, e.g., central Europe in the case of a volcanic eruption in Iceland. In addition, the aircraft in situ measurements used in the previous studies were self-designed (artificial) based on model simulations from which actual conditions might differ significantly. For example, using data of a period of $10 \mathrm{~h}$ by an aircraft gives accurate assimilation results. But in practical situations, a continuous aircraft measurement mission is at most 3 or $4 \mathrm{~h}$, thus it is still uncertain whether the assimilation can produce significant effect with a shorter measurement mission. Therefore, in case of real-life aircraft in situ measurements, it remains unknown whether the ensemblebased data assimilation still has significant improvements on the distal part of volcanic ash clouds and how long the influence will last. The answers of these questions will lead us to a solution for evaluating distal volcanic ash clouds and further provide accurate aviation advice. This study aims at investigating these questions. Note that the term real-life aircraft measurements in this study refer to authentic measurements obtained by real aircrafts. This is to distinguish the artificial aircraft measurements as used in Fu et al. (2015). Another term distal volcanic ash plume is used to clarify the study focuses on volcanic ash forecasts far from the volcano, i.e., continental Europe in this study.

This paper is organized as follows. Section 2 introduces the LOTOS-EUROS model, aircraft in situ measurements, and ensemble-based data assimilation methods used in this study. The assimilation experiments on distal volcanic ash clouds are specified in Sect. 3. Section 4 validates the performance of real-life data assimilation. Section 5 contains the benefit of the improved forecasts of distal ash plume on aviation advice, and also how much and how long the benefit has effect. Finally, the last section summarizes the concluding remarks of our research.

\section{Materials and methods for volcanic ash assimilation}

\subsection{The LOTOS-EUROS model for volcanic ash transport}

In this study, we use the LOTOS-EUROS model (Schaap et al., 2008) to simulate volcanic ash transport and dispersion, which is an operational air-quality model, used for daily air quality forecasts over Europe (Curier et al., 2012), focusing on ozone, nitrogen oxides, and particular matter. The model uses the off-line meteorological data produced by European Center for Medium-Range Weather Forecasts 
Table 1. Volcanic ash particle size distribution and ash bins property for LOTOS-EUROS model simulation.

\begin{tabular}{lrrr}
\hline Bins & $\begin{array}{r}\text { Particle } \\
\text { diameter }\end{array}$ & $\begin{array}{r}\text { Percent of } \\
\text { mass }\end{array}$ & $\begin{array}{r}\text { Average particle } \\
\text { size }(\mu \mathrm{m})\end{array}$ \\
\hline vash_1 & 250 to $2000 \mu \mathrm{m}$ & 29 & 1125.00 \\
vash_2 & 63 to $250 \mu \mathrm{m}$ & 31 & 156.50 \\
vash_3 & 30 to $63 \mu \mathrm{m}$ & 12 & 46.50 \\
vash_4 & 10 to $30 \mu \mathrm{m}$ & 18 & 20.00 \\
vash_5 & 2.5 to $10 \mu \mathrm{m}$ & 8 & 6.25 \\
vash_6 & 0.0 to $2.5 \mu \mathrm{m}$ & 2 & 1.25 \\
\hline
\end{tabular}

(ECMWF). The model is used to produce volcanic ash dispersion simulations in a timely and useful manner for forecasting. To describe a volcanic eruption in LOTOS-EUROS model, eruption source parameters (ESP) such as plume height $(\mathrm{PH})$, mass eruption rate (MER), vertical mass distribution (VMD) and particle size distribution (PSD) are needed. Typically ESPs for different volcanoes are provided as a look up table (Mastin et al., 2009).

The input parameter PH in LOTOS-EUROS is taken from the hourly based plume height detection by Icelandic Meteorological Office (IMO) (Gudmundsson et al., 2012) and usually the uncertainty of $\mathrm{PH}$ is taken as $20 \%$ (Bonadonna and Costa, 2013). For VMD, large explosive volcanic plumes have a typical "umbrella" shaped vertical distribution (Sparks et al., 1997) and as such this "umbrella" shaped VMD is adapted into LOTOS-EUROS (Fu et al., 2015; Lu et al., 2016). The PSD in LOTOS-EUROS is defined as the ESP type S2 (see definitions in Mastin et al., 2009), in which the mass fraction of erupted debris finer than $63 \mu \mathrm{m}$ is 0.4 . For the $\mathrm{S} 2$ type eruption, Durant and Rose (2009) provided the base for the PSD from their analysis of the 1992 Crater Peak, Mount Spurr event. Hence, Table 1 shows the ash distribution based on their analysis and is used in our experiments. Another input parameter MER is very hard to measure for an explosive onsetting volcano. Usually it is calculated from the plume height. Mastin et al. (2009) studied the relation between these parameters and concluded that an empirical relationship between plume height $\mathrm{PH}(\mathrm{km})$ and mass eruption rate MER $\left(\mathrm{kg} \mathrm{s}^{-1}\right)$ is

$\mathrm{PH}=2.00 V^{0.241}$, and $\frac{V}{\mathrm{MER}}=\frac{1.5 e^{3}}{4.0 e^{6}}$,

where $V\left(\mathrm{~m}^{3} \mathrm{~s}^{-1}\right)$ represents the volumetric flow rate.

Recently, the LOTOS-EUROS model has been evaluated as an appropriate volcanic ash transport model (Fu et al., 2015) (Fig. 1a), where the volcanic ash concentrations are described by six aerosol tracers including $\mathrm{PM}_{10}$ and $\mathrm{PM}_{2.5}$ (corresponding to vash_5 + vash_6 and vash_6 in Table 1) to model the transport process. The physical processes that are relevant for volcanic ash are similar as those that apply for mineral dust, e.g., advective transport and diffusion, deposition, coagulation, sedimentation, and resuspension (Lang- mann, 2013). Where the transport is determined by the wind fields could be regarded as rather well known. While the other deposition and sedimentation processes are rather uncertain. For example, the parameterizations for the later processes include assumptions about the particle distribution, which are difficult to summarize in a few bins. These processes act on the distribution of the total ash mass over the modes (particle sizes) and the total mass load; one could therefore state that almost everything in the description of an ash cloud is uncertain, except for the cloud shape and position. The processes included in this study are transport, sedimentation, and wet and dry deposition, where the relevant properties such as average particle size (Table 1) are implemented following Zhang (2001). Processes that are missing yet are for example coagulation, evaporation, and resuspension. They might be considered in the future when appropriate observations are available for constraint, for example sedimentation amounts.

\subsection{Real-life aircraft in situ measurements}

During the period of the Eyjafjallajökull eruption in AprilMay 2010, the outskirts of the eruption plume were entered directly by research flights, delivering most direct measurements within the eruption plume during this eruptive event (Weber et al., 2012). The measurement aircraft (Fig. 1b) was equipped with optical particle counters (OPC) for in situ measurements. Real-time monitoring of the particle concentrations was possible during the flights and in situ measurements from the eruption plume were obtained with high timeand spatial-resolution. Through a direct laboratory calibration experiment, in which the mass concentration obtained with the OPC was compared with the absolute mass concentration gathered on a gravimetric filter, the standard deviation between the gravimetric measurement and the OPC was estimated at $10 \%$ (Weber et al., 2010), which can be taken as the instrumental error for this type of measurements during the performed flight. The total measurement error not only contains the instrumental error, but also includes an estimate of the model representation error (Fu et al., 2015).

In this study we used the aircraft-based measurements taken by one measurement flight on 18 May 2010 performed by the group (Environmental Measurement Techniques) at the university of Applied Sciences in Duesseldorf. The aircraft measures at heights around 3-4 km (Weber et al., 2012) and in northwest Germany including the boundary areas between the Netherlands and Germany, see Fig. 1b (the black rectangular area in Fig. 1a). The aircraft measurement route started from the airfield "Schwarze Heide", headed along the Dutch border in the direction of the North Sea, continued towards Hamburg and then returned to the airfield. During the flight, concentrations of $\mathrm{PM}_{10}$ and $\mathrm{PM}_{2.5}$ were measured, see Fig. 1c and d. 
$(a)_{\text {Tim }}$

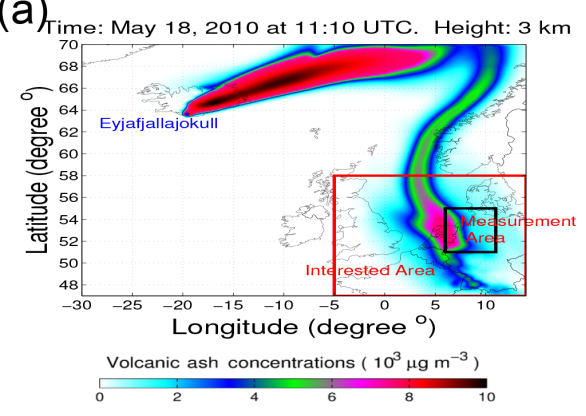

(c)

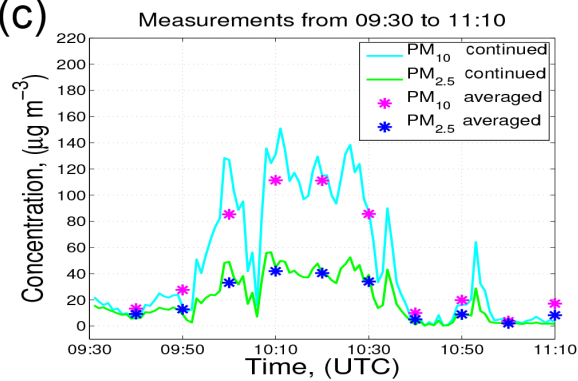

(b)

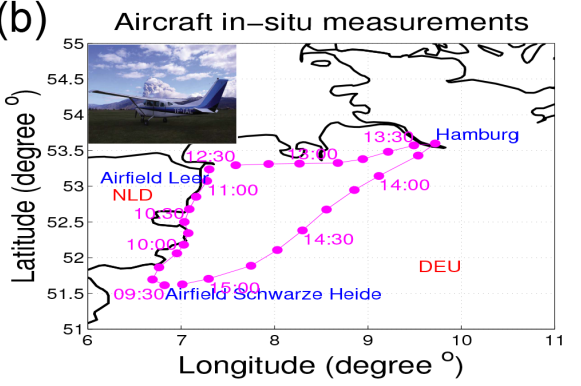

(d)

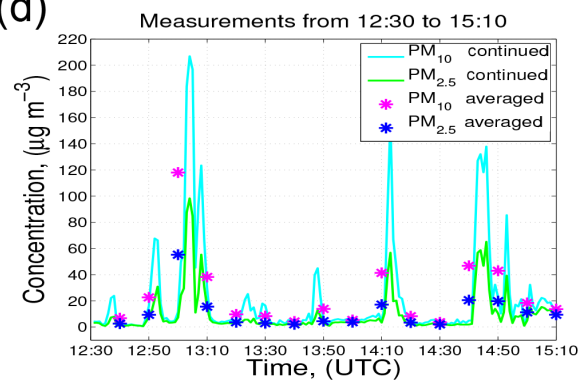

Figure 1. Aircraft in situ measurements of distal volcanic ash plume. (a) The LOTOS-EUROS simulation of volcanic ash plume at 11:10 UTC, 18 May 2010. (b) Measuring aircraft flight route on 18 May 2010. (c) $\mathrm{PM}_{10}$ and $\mathrm{PM}_{2.5}$ measurements from 09:30 to 11:10 UTC. (d) $\mathrm{PM}_{10}$ and $\mathrm{PM}_{2.5}$ measurements from 12:30 to 15:10 UTC. In (c, d), the curves show the values of $\mathrm{PM}_{10}$ and $\mathrm{PM}_{2.5} \mathrm{measured}$ at a frequency of every $6 \mathrm{~s}$. The values marked with a star are the averaged $\mathrm{PM}_{10}$ and $\mathrm{PM}_{2.5}$ (average every $10 \mathrm{~min}$ ) which are used in the LOTOS-EUROS model in accordance with the model simulation step (10 min).

\subsection{The ensemble Kalman filter}

The ensemble-based data assimilation technique used in this study is an ensemble Kalman filter technique (EnKF). Apart from the original formulation (Evensen, 1994), other formulations have been introduced such as the ensemble Kalman smoother (EnKS) (Evensen and van Leeuwen, 2000), ensemble square root filter (EnSR) (Evensen, 2004) and the reduced rank square root filter (RRSQRT) (Verlaan and Heemink, 1997). Ensemble-based assimilation is easy to implement, suitable for real-time estimation of concentrations and has a very general statistical formulation.

The ensemble Kalman filter essentially is a Monte Carlo ensemble-based method (Evensen, 2003), based on the representation of the probability density of the state estimate in an ensemble of $N$ states, $\boldsymbol{\xi}_{1}, \boldsymbol{\xi}_{2}, \ldots, \boldsymbol{\xi}_{N}$. Each ensemble member is assumed to be a single sample out of a distribution of the true state. The number of required ensemble members depends on the complexity of the probability density function to be captured, which is usually determined by the nonlinearity of the model and the description of the involved uncertainties. For volcanic ash assimilation, an ensemble size of 50 is considered acceptable in terms of accuracy while keeping computation time within reach (Fu et al., 2015). For application of the filter algorithm to the LOTOS-EUROS model, in the first step of this algorithm an ensemble of $N$ volcanic ash states $\xi^{\mathrm{a}}(0)$ is generated to represent the uncertainty in the initial condition $\boldsymbol{x}(0)$. In the second step, the forecast step, the LOTOS-EUROS model (with stochastic plume height) propagates the ensemble members from the time $k-1$ to $k$ :

$\xi_{j}^{\mathrm{f}}(k)=M_{k-1}\left(\xi_{j}^{\mathrm{a}}(k-1)\right)$.

The state-space operator $M_{k-1}$ describes the time evolution from the time $k-1$ to $k$ of the state vector which contains the ash concentrations in the model grid boxes. The filter state is a stochastic distribution with mean $\boldsymbol{x}^{\mathrm{f}}$ and covariance $\mathbf{P}^{\mathrm{f}}$ following:

$$
\begin{aligned}
\boldsymbol{x}^{f}(k) & =\left[\sum_{j=1}^{N} \boldsymbol{\xi}_{j}^{f}(k)\right] / N, \\
\mathbf{L}^{f}(k) & =\left[\boldsymbol{\xi}_{1}^{f}(k)-\boldsymbol{x}^{f}(k), \cdots, \boldsymbol{\xi}_{q}^{f}(k)-\boldsymbol{x}^{f}(k)\right], \\
\mathbf{P}^{f}(k) & =\left[\mathbf{L}^{f}(k) \mathbf{L}^{f}(k)^{\mathrm{T}}\right] /(N-1),
\end{aligned}
$$

where the superscript "T" represents the transpose of the matrix. The observational network is defined by the observation operator $H$ that maps state vector $\boldsymbol{x}$ to observation space $\boldsymbol{y}$ :

$\boldsymbol{y}(k)=H_{k}(\boldsymbol{x}(k))+\boldsymbol{v}(k), \quad \boldsymbol{v}(k) \sim N(0, \mathbf{R})$,

where the observation error $\boldsymbol{v}$ is drawn from a Gaussian distribution with zero mean and covariance matrix R. Here, $\boldsymbol{y}$ contains aircraft in situ measurements of ash concentration and $\mathbf{R}$ is filled in a diagonal matrix with the square of the standard deviation of $y$. The operator $H$ then selects the grid 
cell in $x$ that corresponds to the observation location. When measurements become available, the ensemble members are updated in the analysis step using the Kalman gain:

$$
\begin{aligned}
\mathbf{K}(k) & =\left(\mathbf{f} \circ \mathbf{P}^{f}(k)\right) \mathbf{H}(k)^{\mathrm{T}} \\
& {\left[\mathbf{H}(k)\left(\mathbf{f} \circ \mathbf{P}^{f}(k)\right) \mathbf{H}(k)^{\mathrm{T}}+\mathbf{R}\right]^{-1}, } \\
\xi_{j}^{\mathrm{a}}(k) & =\boldsymbol{\xi}_{j}^{f}(k)+\mathbf{K}(k)\left[\boldsymbol{y}(k)-\mathbf{H}(k) \boldsymbol{\xi}_{j}^{f}(k)+\boldsymbol{v}_{j}(k)\right],
\end{aligned}
$$

where $\boldsymbol{v}_{j}$ represents realizations of the observation error $v$.

In Eq. (7), the covariance localization (Houtekamer and Mitchell, 1998, 2001) is obtained using a Schur product $\mathbf{f} \circ \mathbf{P}^{\mathrm{f}}$ (i.e., element-wise multiplication) in order to reduce the spurious correlations caused by the finite ensemble size, which is a general problem in ensemble-based data assimilation. The correlation matrix $\mathbf{f}$ is obtained by applying a correlation function to the Euclidean distance between two points. The correlations decrease to zero beyond a certain distance. This distance-based covariance localization can be easily implemented for eliminating the spurious correlations outside the localized region. For some applications (e.g., ozone, $\mathrm{CO}_{2}$, sulfur dioxide), this approach has achieved an acceptable performance with a simple setup using a constant localization parameter of 50-500 km (Curier et al., 2012; Chatterjee et al., 2012; Barbu et al., 2009). In this study, in order to keep as many real correlations as possible when eliminating spurious correlations for continental Europe, $500 \mathrm{~km}$ is adopted as the localization parameter in volcanic ash assimilation of aircraft in situ measurements.

\section{Sequentially assimilating real-life aircraft in situ measurements for distal volcanic ash clouds}

\subsection{Experimental setup}

As described in Sect. 2, an ensemble Kalman filter (EnKF) is used in this study to assimilate real-life aircraft in situ observations. The LOTOS-EUROS model run starts at 09:00 UTC 14 April 2010 by considering a zero initial condition, equivalent to an assumption of "no ash load yet". The volcanic ash is released during the first guess forecast based on the defined ESPs (PH, MER, VMD, PSD), as discussed in Sect. 2.1. The model state propagates along the numerical simulation with a time step of $10 \mathrm{~min}$; Fu et al., 2015), then the model result is taken as an initial state for the next time step. When the model run arrives at 09:40 UTC 18 May, the ash state of volcanic cloud starts to be continuously corrected by data assimilation through combining real-life aircraft-based measurements taken along the Dutch border until the time of 11:10 UTC 18 May. The specification of uncertainties is important for the success of data assimilation in this study. The stochastic PH is assumed to be temporally correlated and the correlation parameter $\tau$ is set to be $1 \mathrm{~h}$ (Fu et al., 2015). Thus, the $\mathrm{PH}$ noise $\left(N_{\mathrm{ph}}\right)$ at two times $\left(t_{1}\right.$ and $\left.t_{2}\right)$ has the relation
(Evensen, 2009) of $\mathbb{E}\left[N_{\mathrm{ph}}\left(t_{1}\right) \cdot N_{\mathrm{ph}}\left(t_{2}\right)\right]=e^{\frac{-\left|t_{1}-t_{2}\right|}{\tau}}$, where $\mathbb{E}$ represents the mathematical expectation.

To assimilate measurements in a simulation model, it is necessary to quantify the model representation error. The model representation error is the discrepancy between the quantity that instrument observes, and what the model value represents. Concentration values are defined on discrete grids with a finite resolution at discrete time steps. A measurement location usually does not coincide with the grid point where the concentration value is defined. The spatial resolution of the model used in this study is around $12 \mathrm{~km} \times 12 \mathrm{~km} \times 1 \mathrm{~km}$, therefore the volume of one grid-box is about $150 \mathrm{~km}^{3}$. Through model processing, the concentration of one grid-box represents an average value for this grid-box, while one aircraft in situ measurement is a point value in a 3-D field. In this study, we choose the in situ measurement corresponding to the grid-box average value. This approximation makes sense only when two assimilated measurements are positioned in two different grid-boxes. Considering the aircraft speed of $100-200 \mathrm{~km} \mathrm{~h}^{-1}$ and the LOTOSEUROS horizontal and vertical resolution, a $10 \mathrm{~min}$ assimilation frequency is chosen to guarantee different assimilated measurements are in different grid-boxes. The observation therefore almost corresponds to one model state variable in a grid-box, thus the model representation error is probably small. For the moment, we will therefore not explicitly specify a model representation error, but implicitly assume that it is zero. The total observation representation error, defined as the sum of the instrumental error and the model representation error, is taken as $10 \%$ in this study.

Since the real-life measurements of the $\mathrm{PM}_{10}$ and $\mathrm{PM}_{2.5}$ concentrations are available and the uncertainties of this type of measurements are approximately known, ensemble-based data assimilation can be used to combine them with the LOTOS-EUROS model to reconstruct optimal estimates.

\subsection{Evaluation of real-life data assimilation}

It is first examined how the data assimilation actually performs in the system. Figure 2 shows the measurements, the mean of the ensemble members, as well as the forecast and the analysis of selected ensemble members. From the estimation of both volcanic ash components $\mathrm{PM}_{10}$ and $\mathrm{PM}_{2.5}$ (Fig. 2a and b), we find the forecast mean largely overestimates the measurement at every time step, but the overestimation diminishes by the assimilation process significantly. Instead, the analysis mean consistently approximates ("very close") the measurements with a high accuracy. This result illustrates that the assimilation at the measurement location is able to approximate the observed values and also solves the problem of overestimation. Moreover, at the measurement location, the spread in the analysis ensembles is much smaller than that in the forecast ensembles, which means the error variance of analysis value at the measurement locations is significantly reduced through the use of assimilation. This 


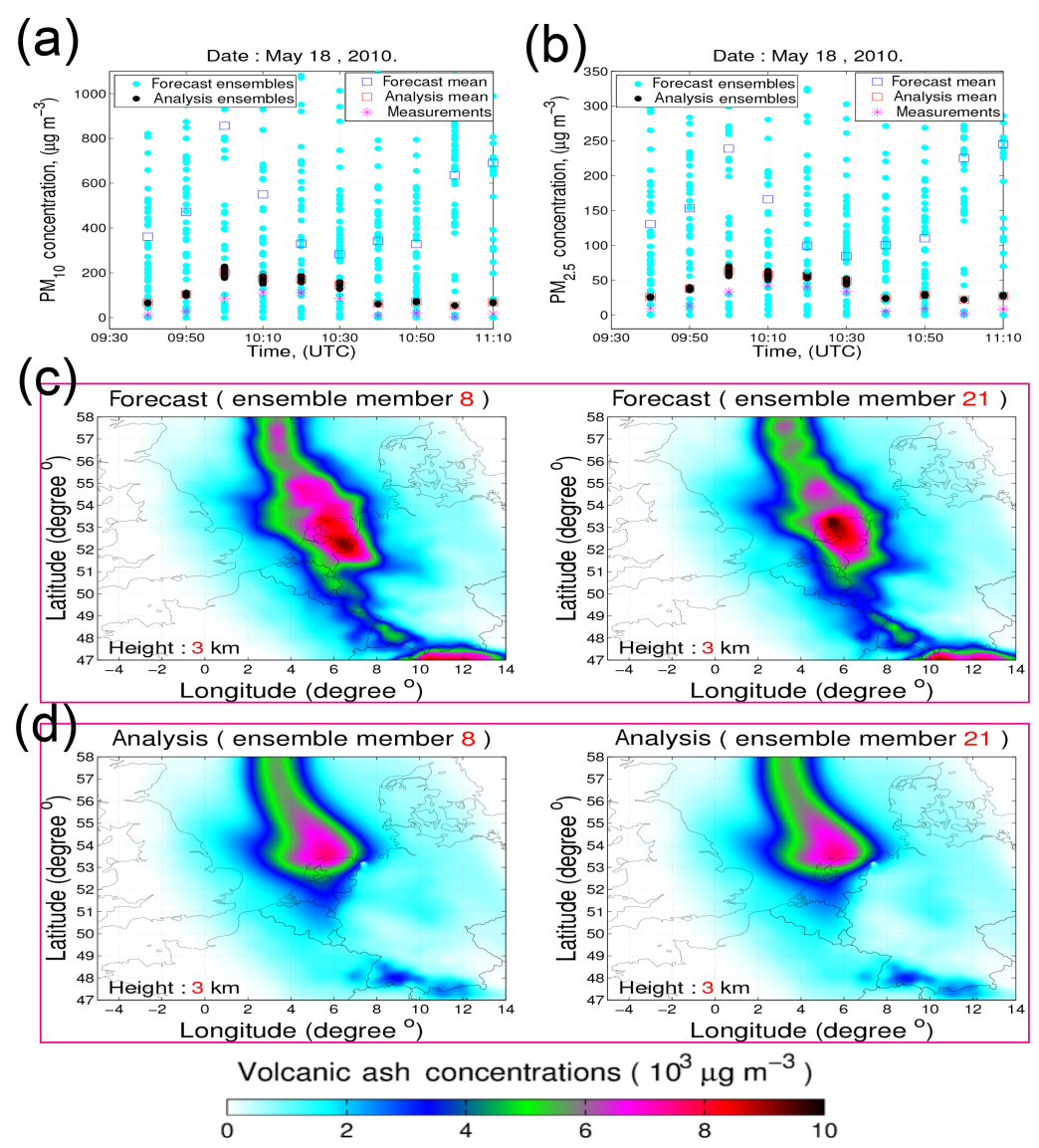

Figure 2. Assimilation effect from 09:40 to 11:10 UTC, 18 May 2010. (a, b) Volcanic ash concentrations of PM 10 and $\mathrm{PM}_{2.5}$ at measurement locations. (c, d) Volcanic ash ensemble state (ensemble member 8 and 21) of forecast and analysis at 11:10 UTC. The measurements, ensembles and mean of forecast and analysis are shown in $(\mathbf{a}, \mathbf{b})$. In $(\mathbf{c}, \mathbf{d})$, the area of interest is marked as red rectangular in Fig. 1a. The evaluation height is chosen at $3 \mathrm{~km}$ since the measurements are taken at altitudes around this height, see Sect. 2.2.

is because aircraft in situ measurements are of high accuracy. Note that Fig. 2a and b only show the ensemble mean and the spread of the ensembles at the measuring locations. However, we also want to know how much impact assimilation of aircraft in situ measurements can have on a wide area of the distal volcanic ash plume. If the impact is only limited to the measurement locations or only a small nearby area of ash plume, there will be no significant improvement in terms of aviation advice because flights need a rather large domain for safety guarantee.

In order to further investigate this effect, we first show the ensembles of uncertain volcanic ash simulations (see Fig. 2c and d), which correspond to the ash distribution at 11:10 UTC 18 May 2010 before and after assimilation. Note that this study focuses on the distal volcanic ash plume, thus only the area of the whole plume marked as red rectangular as shown in Fig. 1a is of interest. Without loss of generality, ensemble member 8 and 21 are chosen for illustrating the ensemble spread of the distal ash plume. Through comparing different ensemble members with respect to the forecast at 11:10 UTC (Fig. 2c), the ensemble forecast member 21 is shown to be very different from the member 8 in almost all the complete distal plume, thus the large error of the forecast is not only at measurement locations, but also in a large area around the measurement. Compared to the forecast, ensembles of analysis state (Fig. 2d) show no large differences across the entire domain of interest. This tells us that assimilating aircraft measurements effectively reduce the ensemble spread of the whole distal ash plume, which is a sign of consistency to the measurement locations.

Next, we investigate the assimilation impact on the ensemble mean over the distal volcanic ash plume. Figure 3 shows examples of the mean at 09:40 and 11:10 UTC 18 May with and without assimilating aircraft measurements. Compared to the case without assimilation at 11:10 UTC (Fig. 3b), large differences can be observed in the simulation results with a continuous assimilation (Fig. 3d). Note that areas with ash concentration higher than $4000 \mathrm{\mu g} \mathrm{m}^{-3}$ are classified as No Fly Zone (NFZ) (EASA, 2015; Fu et al., 2015), which means aviation in these areas is not allowed. After the assimilation process, the calculated volcanic ash concentrations in Germany, Luxembourg and the Netherlands (except in northern 


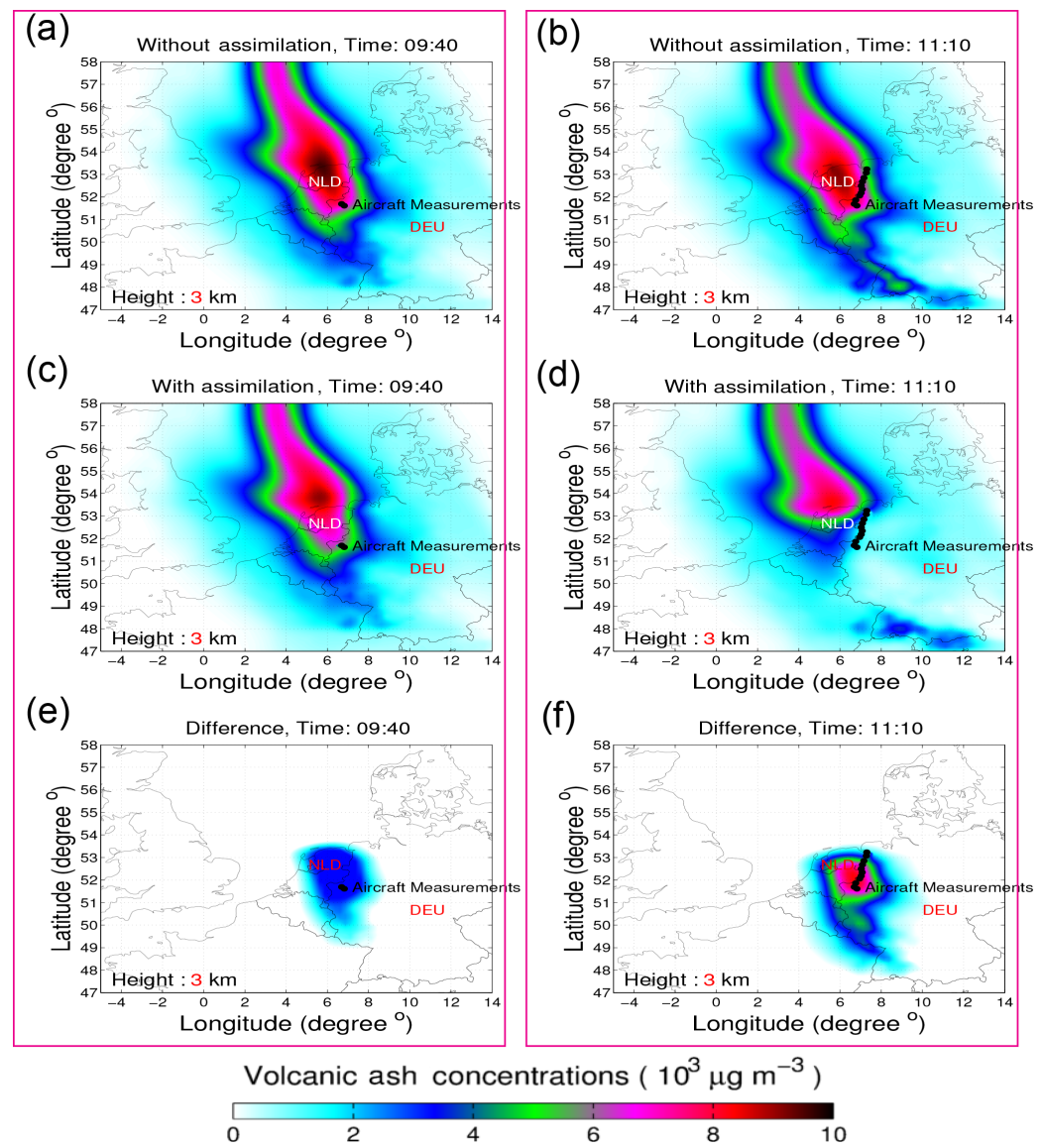

Figure 3. Comparison with and without assimilating aircraft in situ measurements on 18 May 2010. (a, b) Simulation results without assimilation at 09:40 and 11:10 UTC. (c, d), Simulation results with assimilation at 09:40 and 11:10 UTC. (e) Differences of (a, c). (f) Differences of $(\mathbf{b}, \mathbf{d})$. The differences are in absolute values which are obtained by numerically subtracting the values between $(\mathbf{a}, \mathbf{c})$, or $(\mathbf{b}, \mathbf{d})$. Panels $(\mathbf{e}$, f) represent the areas where the assimilation has effect.

Netherlands) have a lower concentration level (lower than $3000 \mu \mathrm{g} \mathrm{m}^{-3}$ ) and the changes on volcanic ash state can be seen across a wide area. This is because the volcanic ash state variables become dependent and correlated due to the transport process (advection and diffusion) and the temporal correlation of emission (Fu et al., 2015). Thus in a fairly large domain, the state change at measurement location also influences state variables in surrounding areas. This is caused by the chosen localization radius (see Sect. 2.3) in the assimilation process. Further, the downwind direction includes influenced state variables due to the transport of earlier corrected ash concentrations, especially regarding forecasts later than the assimilated time steps. Note that after a careful check on the wind field around the aircraft route, the term "downwind" direction means the direction of "South-East", which will be used in the following discussions. Another note is that the differences between with and without assimilation are not obtained in one-time, but step by step with assimilating measurements over a period of one and a half hours from 09:40 to $11: 10$ UTC. This can be seen from the assimilation results at 09:40 and 11:10 UTC (Fig. 3c and d) where clear differences (Fig. 3e and f) between the two times can be observed and the effect of the assimilation at 09:40 UTC is less pronounced than at 11:10 UTC. This shows that after a continuous assimilation of aircraft measurements, the differences with the original simulation are the result of an accumulation of all previous assimilation effects. This analysis also tells us that all the assimilation steps are important for the final result and that only using one or two measurements does not produce accurate results.

\section{Validation of assimilation performance}

Based on the analysis above, significant differences between volcanic ash simulations without and with assimilation have been revealed. To examine whether the assimilated results are indeed more accurate than the model results, a further validation must be conducted. Figure $4 \mathrm{a}$ and $\mathrm{b}$ show the comparison of the forecasted volcanic ash plumes with and without assimilation. The basic idea of this validation is to compare 
(a)

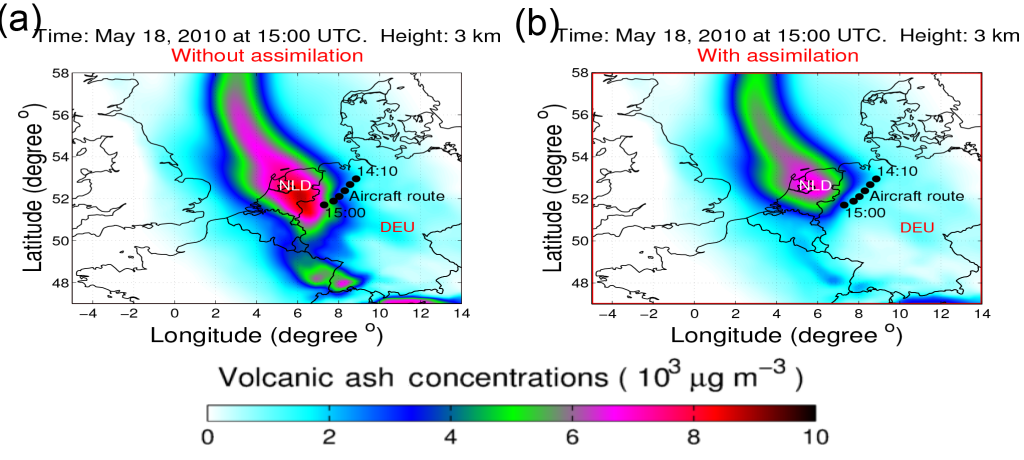

(c)

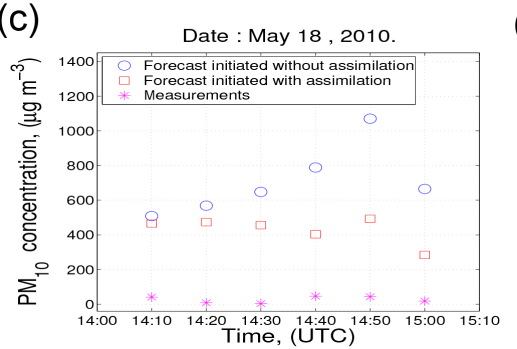

$(\mathrm{b})$

(d)

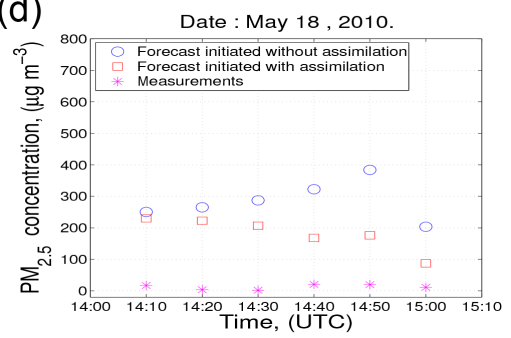

Figure 4. Forecast at 15:00 UTC 18 May 2010 with different initial conditions for the volcanic ash state. (a) Forecast initiated with (Fig. 3b). (b) Forecast initiated with (Fig. 3d). (c) $\mathrm{PM}_{10}$ concentration from 14:10 to 15:00 UTC. (d) $\mathrm{PM}_{2.5}$ concentration from 14:10 to 15:00 UTC.

future in situ measurements with the forecast of the volcanic ash plumes initiated with Fig. $3 \mathrm{~b}$ and d. After the assimilation process, the assimilation influenced region temporally propagates to the downwind direction due to the meteorological drive (wind speed and direction). Thus the forecasted downwind ash concentrations are influenced along the length of integration time after assimilation. Because all the other settings in the system are the same, a better forecast is expected due to a more accurate initial state. We use the measurements from 09:30 to 11:10 UTC along the Dutch border to produce the assimilated results, then we validate the results using another set of aircraft in situ measurements in the downwind direction taken from 14:10 to 15:00 UTC 18 May 2010 (see Fig. $1 \mathrm{~b}$ and d). The validation data are selected carefully with respect to the influenced area (Fig. 3f).

With different initialization, the forecast of volcanic ash concentration at 15:00 UTC shows large differences. The forecast after assimilation (see Fig. 4b, lower than $3000 \mu \mathrm{g} \mathrm{m}^{-3}$ in the downwind direction of the measurement track) is much smaller than that without assimilation (Fig. 4a, higher than $4000 \mathrm{\mu g} \mathrm{m}^{-3}$ in some areas of continental Europe). Note that the forecast for both cases may be performed better by combining adjustments to state variables as well as eruption parameters. The detailed ash concentrations of two forecasts are compared with measurements in Fig. 4c and d. Both forecasts are shown to overestimate the measurements. This is in accordance with practical experience that volcanic ash simulations often overestimate the truth to guarantee a safe aviation advice. This is because in practice, if engine performance experiments cannot be designed in accu- rate and realistic conditions of volcanic ash clouds, cautious approaches (overestimation) to guide commercial flight operations in airspace during volcanic ash transport are often recommended (Prata and Prata, 2012). Furthermore, we can also see that at each validation location, the forecast with assimilation is closer to the measurements than the forecast without assimilation, and also that the overestimation is significantly reduced using assimilation. This shows that the forecast at these locations with assimilation is more accurate than the forecast without assimilation, therefore the assimilated volcanic ash state (Fig. 3d) is a more accurate approximation to the real state of the distal volcanic ash plume. In addition, we conclude that the assimilation process performs well in combining with the LOTOS-EUROS transport model with real-life measurements.

\section{Assimilation benefit for aviation community}

Next it will be investigated what is the benefit of the improved forecasts of distal ash plume on aviation advice, and also how much and how long the benefit has an effect. Firstly, the assimilation impact in the downwind and upwind directions is considered. For this investigation, five big cities around the measurement route are selected (see Fig. 5a). They are Dortmund, Cologne, Luxembourg in the downwind direction and Amsterdam, Rotterdam in the upwind direction. The evaluation height is chosen at $3 \mathrm{~km}$. For some continental or intercontinental passenger flights, $3 \mathrm{~km}$ might be of special interest regarding taking off and landing. The evaluation time is chosen to be 11:10 UTC 18 May 2010 when 
(a)

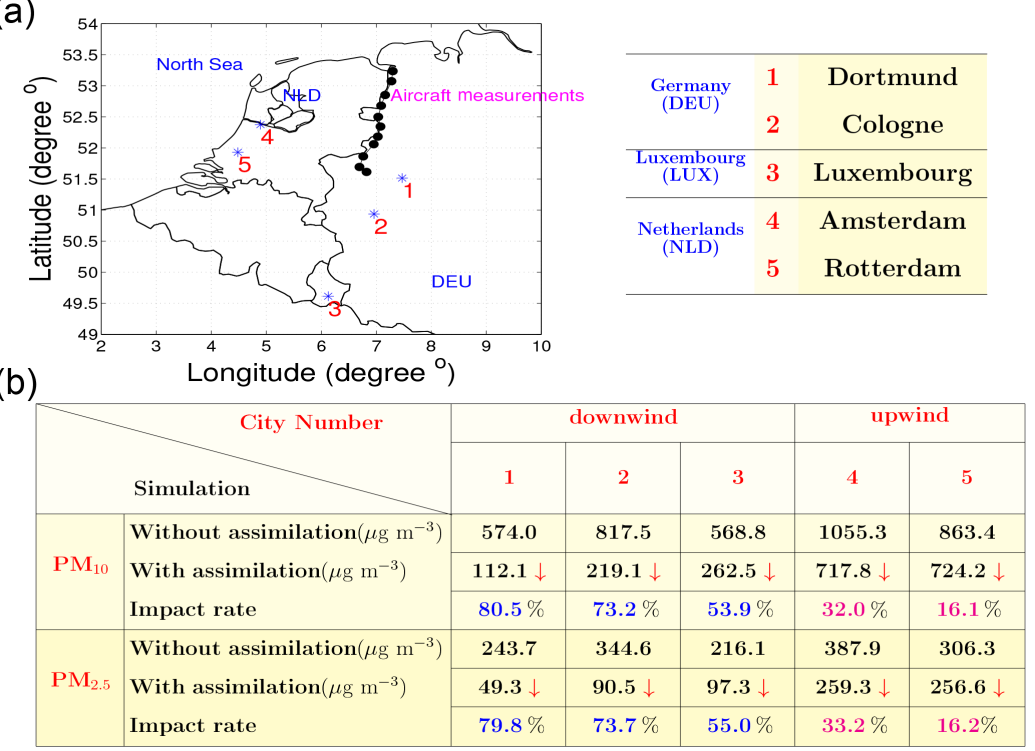

Figure 5. $\mathrm{PM}_{10}$ and $\mathrm{PM}_{2.5}$ evaluation on selected cities with and without assimilation. (a) Selected international cities around the aircraft measurement track. City 1-3 are in the downwind direction, while city 4-5 are in the upwind direction. (b) Concentrations of $\mathrm{PM}_{10}$ and $\mathrm{PM}_{2.5}$ and the quantified impact rates on selected cities. The height of interest is chosen at $3 \mathrm{~km}$. The red arrow represents the trend of concentration values due to the assimilation process. The impact rates in downwind and upwind cases are distinguished by blue and magenta colors.

the assimilation process finishes. The concentrations of two major distal volcanic ash components, i.e., $\mathrm{PM}_{10}$ and $\mathrm{PM}_{2.5}$ (Webley et al., 2012; Fu et al., 2015), are evaluated. Figure 5b shows that results with assimilation is lower for both $\mathrm{PM}_{10}$ and $\mathrm{PM}_{2.5}$ in all the selected cities. To quantify this impact on estimation of both ash components, an impact rate (IR) is introduced for quantification. The IR is defined as

$(\operatorname{IR})_{p}(i)=\frac{(\operatorname{SimuNoAssimi})_{p}(i)-(\operatorname{SimuAssimi})_{p}(i)}{(\operatorname{SimuNoAssimi})_{p}(i)}$,

where $p$ means either $\mathrm{PM}_{10}$ or $\mathrm{PM}_{2.5}, i$ means index of selected cities. Moreover, (SimuNoAssimi) $p$ and (SimuAssimi $)_{p}$ represent two simulations without or with assimilation. Using this equation, we can get the IR of all cities (see Fig. 5b). Based on the IR values, we find the assimilation impact in the downwind direction (Dortmund, Cologne and Luxembourg) are much more significant than those in the upwind direction (Amsterdam, Rotterdam). This means after assimilation, the most significant impact on ash clouds is in the downwind direction where in this study it is mainly Germany (see assimilation impact areas in Fig. 3f).

The analysis above demonstrates that assimilating aircraft in situ measurements has the ability to impact on regional volcanic ash clouds, especially in the downwind direction of the measurement route. It is also shown that assimilation has an impact on aviation advice. If there is no assimilation employed (see Fig. 3b), the volcanic ash concentration in the main transport direction of the distal ash plume reaches over $4000 \mu \mathrm{g} \mathrm{m}^{-3}$. Thus, only relying on simulation results, the aviation advice on continental Europe is that the sky above the North Sea, the Netherlands and the western part of Germany is forbidden for flights. This aviation advice would shutdown flights in a large area. Because the Netherlands and Germany are important aviation hubs in Europe, imposing such a no-fly zone will affect all flights in the ash penetrated area and subsequently leads to a huge economic loss. In contrast, if based on the improved simulation after a continuous assimilation (Fig. 3d), the aviation advice would have been changed. The sky in large parts of Europe is open for commercial flights, because except in small parts of the Netherlands ash concentrations all over the domain of interest are lower than $3000 \mathrm{\mu g} \mathrm{m}^{-3}$. This illustrates that the accuracy of aviation advice and the NFZ area can significantly benefit from the ensemble-based data assimilation process. Note that we give the aviation advice only on the strength of the results at $3 \mathrm{~km}$ height. Generally all model levels must be analyzed for real cases. And the real aviation advice also includes for which exact area and which time frame the advice is given.

Another question is how long the effect of improvement by assimilating aircraft measurements will last? The answer of this will provide us with guidance on how often aircraft measuring should be performed. For investigating the time period of the assimilation impact, the volcanic ash plume is forecasted 1 day (Fig. 6) starting at 11:10 UTC 18 May 2010. Without loss of generality, $\mathrm{PM}_{10}$ is chosen to analyze the forecast performance. Three time snapshots in Fig. $6 \mathrm{a}-\mathrm{c}$ are 

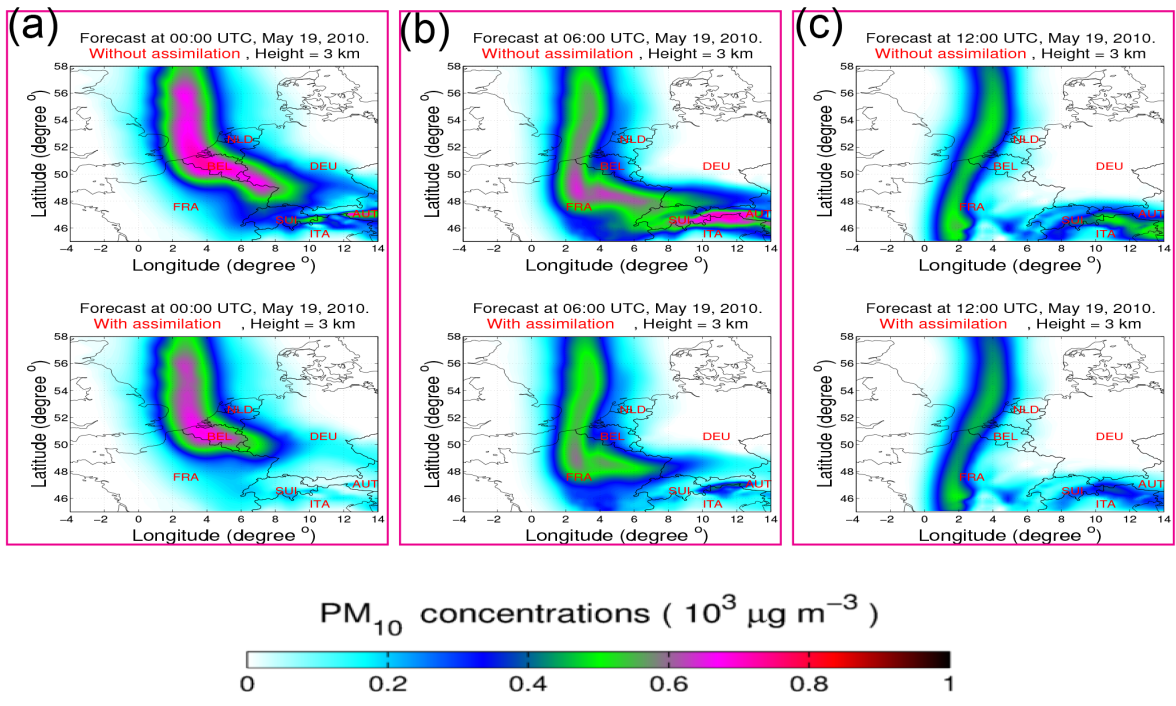

Figure 6. One-day forecast of $\mathrm{PM}_{10}$ concentration with and without assimilation. A larger domain is chosen in this figure (compared to Figs. 2, 3, 4) to demonstrate the downwind change (with time) of the assimilation influenced area. (a) Forecast at 00:00 UTC 19 May 2010. (b) Forecast at 06:00 UTC 19 May 2010. (c) Forecast at 12:00 UTC 19 May 2010.

chosen to show the forecast differences between without and with assimilation. Since there are clear differences between the two cases, the assimilation impact can last 1 day. Note that this impact duration is only valid for the areas (especially for regions downwind to the assimilated observations), that are influenced by the assimilation, which changes with time. When forecasting $24 \mathrm{~h}$ (Fig. 6c), differences still can be observed, but the impact of assimilation is obviously getting much smaller (compared to Fig. 6a and b). Actually we also examined the assimilation impact in the forecast of the next day and observed only very small differences. Therefore, the time period of the assimilation impact of this case study can be taken as $24 \mathrm{~h}$. From this analysis, we suggest the frequency of the measurement campaign to be once per day. This study can be used to provide guidelines for an optimal flight schedule in regional measurement tasks. Note that the impact time investigated is based on the meteorological information in distal volcanic ash plume during the period considered in this study. For other cases, the duration of effective assimilation could be differed.

\section{Conclusions}

In this study, aircraft in situ measurements in distal volcanic ash clouds were assimilated in the LOTOS-EUROS model. During a continuous assimilation, the error of the analyzed volcanic ash state was significantly reduced through assimilating real-life in situ measurements. The improved volcanic ash state after assimilation are the result of an accumulation of all previous assimilation effects. It was shown that all the assimilation steps contribute to the final result. To examine whether the assimilated volcanic ash state was indeed more accurate than the conventional simulation, a validation with future in situ measurements was conducted. The forecast with assimilation was shown more accurate than the conventional forecast without assimilation. It also concluded that the assimilation process performed well in combining with the LOTOS-EUROS transport model with real-life measurements.

The validation results also revealed that with the transport models alone, it is difficult to accurately model volcanic ash movements. This is probably because model parameters (e.g., the plume height) are uncertain and some processes are missing, for example, coagulation, evaporation, and resuspension. Analysis of the results showed that the data assimilation approach used herein is able to compensate some of the model's deficiencies. Aircraft in situ measurements have a high accuracy and plays an important role to a successful data assimilation. The aircraft can enter the plume to selectively obtain observations, so that the measurements are in situ and optimal for the ensemble-based data assimilation methodology.

Investigation was also carried out on the benefit of the improved forecasts of distal ash plume on aviation advice. We found that after assimilation, the most significant improvements on distal ash clouds are in the downwind direction where in this study it is mainly Germany. This phenomenon is due to the wind direction and the transport process during the continuous assimilation. Investigation shows that the accuracy of aviation advice within the assimilation influenced area can significantly benefit from the ensemble-based data assimilation process. The computer experiment revealed that the time period of the improvement effect on the areas downwind to the assimilated observations can be taken as $24 \mathrm{~h}$. 
Based on this result, we suggest to schedule an aircraft measurement campaign at a frequency of once per day. This can be used to provide guidelines for planning future regional measurement tasks. The suggested frequency should be adjusted by the temporal strength (due to wind induced transport) on the assimilation influenced area.

In this study, we applied an off-line approach for model running and simply used the deterministic meteorological input data. These data also contain uncertainties that influence ash cloud transport. In future work, in order to further improve the accuracy of ash forecasting, uncertainties in the meteorological data such as wind speed should also be considered. In this study, only aircraft in situ measurements are used in a data assimilation system. We may expect that with other types of measurements (e.g., satellite-based or lidarbased) together, the assimilation results will be more practical since the aircraft measurements cannot be always obtained. However, for this multi-observation data assimilation, other problems need to be first considered such as insufficient vertical resolution in certain satellite data. This is a difficult aspect for assimilating these data in a 3-D model, and will be investigated in our future work.

\section{Data availability}

The averaged aircraft in situ data used in this study are available from Fig. 1c, d. The continuous aircraft data and the model output data can be accessed by request (g.fu@ tudelft.nl).

Author contributions. All authors participated in the design and analysis of the assimilation experiment. Guangliang Fu, Arjo Segers carried out the LOTOS-EUROS modeling volcanic ash transport. Konradin Weber validated real-life aircraft in situ measurements and provided them for the data assimilation experiment. Guangliang Fu, Hai-Xiang Lin, Arnold Heemink analyzed the results and wrote the paper with contributions from all co-authors.

Acknowledgements. In this paper, OpenDA software (www.openda.com) was used to perform ensemble-based data assimilation. We are very grateful to the editor and reviewers for their reviews and insightful comments. We thank Claire Taylor for her kindly assisting with correction of English grammars. We thank the research funds by China Scholarship Council, Delft University of Technology. We also thank SURFsara, the Netherlands Supercomputing Centre in Amsterdam for providing the Cartesius cluster as the computing facility in the parallel computing experiments (contract No. SH-332-15).

Edited by: P. Stier

Reviewed by: two anonymous referees

\section{References}

Barbu, A. L., Segers, A. J., Schaap, M., Heemink, A. W., and Builtjes, P. J. H.: A multi-component data assimilation experiment directed to sulphur dioxide and sulphate over Europe, Atmos. Environ., 43, 1622-1631, doi:10.1016/j.atmosenv.2008.12.005, 2009.

Bocquet, M., Elbern, H., Eskes, H., Hirtl, M., Žabkar, R., Carmichael, G. R., Flemming, J., Inness, A., Pagowski, M., Pérez Camaño, J. L., Saide, P. E., San Jose, R., Sofiev, M., Vira, J., Baklanov, A., Carnevale, C., Grell, G., and Seigneur, C.: Data assimilation in atmospheric chemistry models: current status and future prospects for coupled chemistry meteorology models, Atmos. Chem. Phys., 15, 5325-5358, doi:10.5194/acp-15-53252015, 2015.

Bonadonna, C. and Costa, A.: Plume height, volume, and classification of explosive volcanic eruptions based on the Weibull function, B. Volcanol., 75, 1-19, doi:10.1007/s00445-013-0742$1,2013$.

Bonadonna, C., Folch, A., Loughlin, S., and Puempel, H.: Future developments in modelling and monitoring of volcanic ash clouds: outcomes from the first IAVCEI-WMO workshop on Ash Dispersal Forecast and Civil Aviation, B. Volcanol., 74, 1-10, doi:10.1007/s00445-011-0508-6, 2012.

Casadevall, T. J.: The 1989-1990 eruption of Redoubt Volcano, Alaska: impacts on aircraft operations, J. Volcanol. Geoth. Res., 62, 301-316, 1994.

Chatterjee, A., Michalak, A. M., Anderson, J. L., Mueller, K. L., and Yadav, V.: Toward reliable ensemble Kalman filter estimates of $\mathrm{CO}_{2}$ fluxes, J. Geophys. Res., 117, D22306, doi:10.1029/2012jd018176, 2012.

Curier, R. L., Timmermans, R., Calabretta-Jongen, S., Eskes, H., Segers, A., Swart, D., and Schaap, M.: Improving ozone forecasts over Europe by synergistic use of the LOTOS-EUROS chemical transport model and in-situ measurements, Atmos. Environ., 60, 217-226, doi:10.1016/j.atmosenv.2012.06.017, 2012.

Durant, A. J. and Rose, W. I.: Sedimentological constraints on hydrometeor-enhanced particle deposition: 1992 Eruptions of Crater Peak, Alaska, J. Volcanol. Geoth. Res., 186, 40-59, doi:10.1016/j.jvolgeores.2009.02.004, 2009.

EASA (European Aviation Safety Agency): EASA Safety Information Bulletin 2010-17R7, available at: http://ad.easa.europa.eu/ ad/2010-17R7 (last access: 22 July 2016), 2015.

Eliasson, J., Palsson, A., and Weber, K.: Monitoring ash clouds for aviation, Nature, 475, p. 455, doi:10.1038/475455b, 2011.

Emeis, S., Forkel, R., Junkermann, W., Schäfer, K., Flentje, H., Gilge, S., Fricke, W., Wiegner, M., Freudenthaler, V., Groß, S., Ries, L., Meinhardt, F., Birmili, W., Münkel, C., Obleitner, F., and Suppan, P.: Measurement and simulation of the 16/17 April 2010 Eyjafjallajökull volcanic ash layer dispersion in the northern Alpine region, Atmos. Chem. Phys., 11, 2689-2701, doi:10.5194/acp-11-2689-2011, 2011.

Evensen, G.: Sequential data assimilation with a nonlinear quasi-geostrophic model using Monte Carlo methods to forecast error statistics, J. Geophys. Res., 99, 10143-10162, doi:10.1029/94jc00572, 1994.

Evensen, G.: The Ensemble Kalman Filter: theoretical formulation and practical implementation, Ocean Dynam., 53, 343-367, doi:10.1007/s10236-003-0036-9, 2003. 
Evensen, G.: Sampling strategies and square root analysis schemes for the EnKF, Ocean Dynam., 54, 539-560, doi:10.1007/s10236004-0099-2, 2004.

Evensen, G.: Data Assimilation - The Ensemble Kalman Filter, Springer, 2nd Edn., 2009.

Evensen, G. and van Leeuwen, P. J.: An Ensemble Kalman Smoother for Nonlinear Dynamics, Mon. Weather Rev., 128, 1852-1867, doi:10.1175/15200493(2000)128<1852:aeksfn>2.0.co;2, 2000.

Fu, G., Lin, H. X., Heemink, A. W., Segers, A. J., Lu, S., and Palsson, T.: Assimilating aircraft-based measurements to improve Forecast Accuracy of Volcanic Ash Transport, Atmos. Environ., 115, 170-184, doi:10.1016/j.atmosenv.2015.05.061, 2015.

Gudmundsson, M. T., Thordarson, T., Höskuldsson, A., Larsen, G., Björnsson, H., Prata, F. J., Oddsson, B., Magnússon, E., Högnadóttir, T., Petersen, G. N., Hayward, C. L., Stevenson, J. A., and Jónsdóttir, I.: Ash generation and distribution from the AprilMay 2010 eruption of Eyjafjallajökull, Iceland, Scientific Reports, 2, 572, doi:10.1038/srep00572, 2012.

Houtekamer, P. L. and Mitchell, H. L.: Data Assimilation Using an Ensemble Kalman Filter Technique, Mon. Weather Rev., 126, 796-811, doi:10.1175/15200493(1998)126<0796:dauaek>2.0.co;2, 1998.

Houtekamer, P. L. and Mitchell, H. L.: A Sequential Ensemble Kalman Filter for Atmospheric Data Assimilation, Mon. Weather Rev., 129, 123-137, doi:10.1175/15200493(2001)129<0123:asekff>2.0.co;2, 2001.

Langmann, B.: Volcanic Ash versus Mineral Dust: Atmospheric Processing and Environmental and Climate Impacts, ISRN Atmospheric Sciences, 2013, 1-17, doi:10.1155/2013/245076, 2013.

Lu, S., Lin, H. X., Heemink, A. W., Fu, G., and Segers, A. J.: Estimation of Volcanic Ash Emissions Using Trajectory-Based 4D-Var Data Assimilation, Mon. Weather Rev., 144, 575-589, doi:10.1175/mwr-d-15-0194.1, 2016.

Macedonio, G., Costa, A., Scollo, S., and Neri, A.: Effects of eruption source parameter variation and meteorological dataset on tephra fallout hazard assessment: example from Vesuvius (Italy), J. Appl. Volcanol., 5, 5, doi:10.1186/s13617-016-0045-2, 2016.

Mastin, L. G., Guffanti, M., Servranckx, R., Webley, P., Barsotti, S., Dean, K., Durant, A., Ewert, J. W., Neri, A., Rose, W. I., Schneider, D., Siebert, L., Stunder, B., Swanson, G., Tupper, A., Volentik, A., and Waythomas, C. F.: A multidisciplinary effort to assign realistic source parameters to models of volcanic ash-cloud transport and dispersion during eruptions, J. Volcanol. Geoth. Res., 186, 10-21, doi:10.1016/j.jvolgeores.2009.01.008, 2009.

Melville, C. P.: Volcanic Hazards. A Sourcebook on the Effects of Eruptions by R. J. Blong, Disasters, 10, 238-240, doi:10.1111/j.1467-7717.1986.tb00595.x, 1986.

Prata, A. J. and Prata, A. T.: Eyjafjallajökull volcanic ash concentrations determined using Spin Enhanced Visible and Infrared Imager measurements, J. Geophys. Res.-Atmos., 117, D00U23, doi:10.1029/2011jd016800, 2012.

Schaap, M., Timmermans, R. M. A., Roemer, M., Boersen, G. A. C., Builtjes, P. J. H., Sauter, F. J., Velders, G. J. M., and Beck, J. P.: The LOTOS EUROS model: description, validation and latest developments, Int. J. Environ. Pollut., 32, 270-290, doi:10.1504/ijep.2008.017106, 2008.
Schumann, U., Weinzierl, B., Reitebuch, O., Schlager, H., Minikin, A., Forster, C., Baumann, R., Sailer, T., Graf, K., Mannstein, H., Voigt, C., Rahm, S., Simmet, R., Scheibe, M., Lichtenstern, M., Stock, P., Rüba, H., Schäuble, D., Tafferner, A., Rautenhaus, M., Gerz, T., Ziereis, H., Krautstrunk, M., Mallaun, C., Gayet, J.F., Lieke, K., Kandler, K., Ebert, M., Weinbruch, S., Stohl, A., Gasteiger, J., Groß, S., Freudenthaler, V., Wiegner, M., Ansmann, A., Tesche, M., Olafsson, H., and Sturm, K.: Airborne observations of the Eyjafjalla volcano ash cloud over Europe during air space closure in April and May 2010, Atmos. Chem. Phys., 11, 2245-2279, doi:10.5194/acp-11-2245-2011, 2011.

Sparks, R. S. J., Burski, M. I., Carey, S. N., Gilbert, J. S., Glaze, L. S., Sigurdsson, H., and Woods, A. W.: Volcanic Plumes, Wiley, 1st Edn., available at: http://www.worldcat.org/ isbn/0471939013 (last access: 22 July 2016), 1997.

Stohl, A., Prata, A. J., Eckhardt, S., Clarisse, L., Durant, A., Henne, S., Kristiansen, N. I., Minikin, A., Schumann, U., Seibert, P., Stebel, K., Thomas, H. E., Thorsteinsson, T., Tørseth, K., and Weinzierl, B.: Determination of time- and height-resolved volcanic ash emissions and their use for quantitative ash dispersion modeling: the 2010 Eyjafjallajökull eruption, Atmos. Chem. Phys., 11, 4333-4351, doi:10.5194/acp-11-4333-2011, 2011.

Verlaan, M. and Heemink, A. W.: Tidal flow forecasting using reduced rank square root filters, Stoch. Hydrol. Hydraul., 11, 349368, doi:10.1007/bf02427924, 1997.

Weber, K., Vogel, A., Fischer, C., van Haren, G., and Pohl, T.: Airborne measurements of the Eyjafjallajökull volcanic ash plume over northwestern Germany with a light aircraft and an optical particle counter: first results, 7832, 78320P, doi:10.1117/12.869629, 2010.

Weber, K., Eliasson, J., Vogel, A., Fischer, C., Pohl, T., van Haren, G., Meier, M., Grobéty, B., and Dahmann, D.: Airborne insitu investigations of the Eyjafjallajökull volcanic ash plume on Iceland and over north-western Germany with light aircrafts and optical particle counters, Atmos. Environ., 48, 9-21, doi:10.1016/j.atmosenv.2011.10.030, 2012.

Webley, P. W., Steensen, T., Stuefer, M., Grell, G., Freitas, S., and Pavolonis, M.: Analyzing the Eyjafjallajökull 2010 eruption using satellite remote sensing, lidar and WRF-Chem dispersion and tracking model, J. Geophys. Res., 117, D00U26, doi:10.1029/2011jd016817, 2012.

Webster, H. N., Thomson, D. J., Johnson, B. T., Heard, I. P. C., Turnbull, K., Marenco, F., Kristiansen, N. I., Dorsey, J., Minikin, A., Weinzierl, B., Schumann, U., Sparks, R. S. J., Loughlin, S. C., Hort, M. C., Leadbetter, S. J., Devenish, B. J., Manning, A. J., Witham, C. S., Haywood, J. M., and Golding, B. W.: Operational prediction of ash concentrations in the distal volcanic cloud from the 2010 Eyjafjallajökull eruption, J. Geophys. Res., 117, D00U08, doi:10.1029/2011jd016790, 2012.

Winker, D. M., Liu, Z., Omar, A., Tackett, J., and Fairlie, D.: CALIOP observations of the transport of ash from the Eyjafjallajökull volcano in April 2010, J. Geophys. Res.-Atmos., 117, D00U15, doi:10.1029/2011jd016499, 2012.

Zehner, C. (Ed.): Monitoring Volcanic Ash From Space, ESA communication Production Office, Frascati, Italy, 2010.

Zhang, L.: A size-segregated particle dry deposition scheme for an atmospheric aerosol module, Atmos. Environ., 35, 549-560, doi:10.1016/s1352-2310(00)00326-5, 2001. 